\title{
Diplomatas de farda. A França e o golpe de 1964
}

\section{Diplomats in Uniform. France and the 1964 Coup}

Rodrigo Nabuco de Araujo* rodrigo.nabuco@gmail.com

Resumo: Este trabalho analisa o impacto das negociações militares na resolução de conflitos diplomáticos, entre a França e o Brasil, de João Goulart a Costa e Silva. Busca-se compreender o papel do adido militar, secretário para as relações militares, em momentos de ruptura política. Enquanto vários adidos brasileiros se sucedem na embaixada em Paris, diante da fragilidade das relações bilaterais e da importância dos acontecimentos políticos no Brasil, no Rio de Janeiro, o adido francês representa a continuidade dos negócios, devido às afinidades entre militares anticomunistas, franceses e brasileiros. Desse modo, o reatamento do diálogo pode ser compreendido como o resultado da relação pessoal entre os diplomatas de farda e os principais atores do golpe de 1964. Observa-se que os militares franceses se mantiveram à frente da chancelaria francesa, e, habilmente, conseguiram solucionar os principais conflitos entre os dois países, ao prepararem o reconhecimento do governo militar. Oficiais e diplomatas do entourage do presidente de Gaulle, veteranos da Résistance e das guerras coloniais buscavam realizar o projeto gaullista de reconquista da América Latina.

Palavras-chaves: Diplomacia, Relações Brasil-França, Golpe de 1964

Abstract: This article analyzes the impact of military negotiations on the resolution of diplomatic conflicts between France and Brazil from the government of João Goulart to that of Costa e Silva. It attempts to understand the role of the military attaché, secretary for military relations, during a period of political disruption. Several Brazilian military attachés succeeded one another in the Embassy in Paris. Yet, faced with the weaknesses of bilateral relations and the importance of political events in Brazil, the French attache in Rio de Janeiro represents the continuity of the affairs due to the affinities between Brazilian and French anti-communist army officers. Thus, the renewal of talks can be understood as a result of the personal relationship between diplomats in uniform and the main actors of the 1964 military coup. The study demonstrates that French army officers remained ahead of the French Foreign Ministry and were efficiently able to resolve the main conflicts between the two countries as they worked to recognize Brazil's military government. Army officers and diplomats of president de Gaulle's entourage, veterans of the Résistance and the colonial wars sought to achieve the Gaullist project of Latin America's regaining.

Keywords: Diplomacy, Brazil-France relations, 1964 Coup

* Professor associado em Estudos Latino-Americanos da Université de Reims Chamapgne-Ardenne e membro do Centre Interdisciplinaire de Recherches sur les Langues et la Pensée (CIRLEP) - EA 4299. 


\section{Introdução}

O escopo principal deste trabalho é o impacto do golpe civil e militar de 1964 sobre as relações francobrasileiras e o papel dos adidos militares na diplomacia. Busca-se compreender a importância das relações exteriores na estratégia de legitimação do governo Castello Branco, através o olhar dos diplomatas franceses, bem como medir o grau de autonomia dos militares dentro do projeto da diplomacia francesa no Brasil.

Enquanto vários adidos brasileiros se sucedem na embaixada em Paris, diante da fragilidade das relações bilaterais e da importância dos acontecimentos políticos no Brasil, no Rio de Janeiro, o adido francês representa a continuidade dos negócios, em parte, graças às afinidades entre militares anticomunistas franceses e brasileiros. O reatamento do diálogo pode ser compreendido como resultado da relação pessoal entre os diplomatas de farda e os militares no poder. Busca-se nesse sentido elucidar o impacto do golpe de 1964 sobre as relações franco-brasileiras e qual o papel desempenhado pelos adidos militares.

Dirigida pelo adido francês, a bem-sucedida busca operacional proporcionou ao governo do general de Gaulle informações que posicionariam a França como um dos principais parceiros do novo governo brasileiro. A perspectiva da viagem do presidente francês ao redor da América Latina também criava expectativa acerca do reatamento das relações, que nos últimos meses do governo de João Goulart haviam esfriado devido a problemas políticos e financeiros. A chegada dos militares ao poder tornava o oficial à frente da adidância um ator incontornável das relações diplomáticas, mas a situação inédita não foi suficiente para quebrar o paradigma do governo de Gaulle, segundo o qual os militares colaboravam diretamente nas tomadas de decisões, mas restringiam-se ao papel de instrumentos do executivo. Apesar de estarem disposto a empregar todos os meios necessários para realizar o projeto gaullista de reconquista da América Latina, a análise da documentação revela que contrariamente aos adidos, os diplomatas de carreira não estavam dispostos a reconhecer governos de natureza ditatorial sem garantias constitucionais. $\mathrm{O}$ conflito entre adidos e embaixadores foi constante e limitou os resultados do projeto, que se concretizariam somente anos mais tarde, através do comércio de armas.

A embaixada francesa é observada como centro de intensa atividade política, nomeadamente em torno de dois adidos militares, Henri Lemond e Pierre Lallart. A personalidade deles é fator crucial no restabelecimento das relações diplomáticas, pois o período considerado é marcado por rupturas entre os governos francês e brasileiro. A queda de Goulart surgiu assim como uma oportunidade de retomar relações, na qual a atuação do adido militar foi muito além da coordenação dos serviços de segurança e informação, pois coube a ele estabelecer contatos com as redes clandestinas de golpistas. Apesar de vinculados diretamente à autoridade do embaixador, eles gozavam de certa autonomia, agindo mais como diplomatas que como soldados, buscando solucionar os problemas sem o uso da força (DOISE, VAÏSSE, 1988, p. 288).

A política externa francesa foi marcada pela forte personalidade dos homens do entourage de Pierre Messmer, ministro da Defesa, que serviram de intermediários entre os militares brasileiros e a representação diplomática: veteranos da Résistence bem como das guerras coloniais, tinham grande experiência de atuação no Serviço de Documentação Exterior e de Contraespionagem, o serviço secreto francês. No Brasil depois do golpe, tinham por missão reorganizar as redes de informações e criar condições para uma nova cooperação franco-brasileira.

Este capítulo se divide em quatros momentos. Após analisar alguns aspectos da presença militar fran- 
cesa no Brasil antes do golpe de 1964, busca-se evidenciar as principais redes de relações dos adidos franceses no Brasil. Torna-se clara a relação que diplomatas franceses mantinham com setores conservadores do empresariado brasileiro. Diante do arquipélago das conspirações, a embaixada francesa toma posição a favor dos golpistas, revelando a importância do reconhecimento internacional para os militares no poder, que buscavam assim legitimar sua hegemonia. Por fim, tenta-se compreender em que medida a obsessão em manter uma imagem positiva do Brasil no exterior conduz à troca de informações com a França acerca da atividade de determinados exilados políticos. Através desse texto, buscase mostrar que o reconhecimento internacional do golpe era fundamental na estratégia de legitimação do governo Castello Branco.

\section{Militares e diplomatas entre dependência e autonomia}

Ao assumir o posto de adido militar no Rio de Janeiro, em janeiro de 1959, o coronel Henri Lemond, oficial de estado-maior, veterano das guerras da Indochina e da Argélia, se mostrou fiel aos princípios anunciados por seu predecessor: consolidou relações com militares brasileiros nacionalistas, valorizou a penetração ideológica da doutrina francesa e consolidou contato com oficiais brasileiros. Era necessário valorizar a nova orientação da política externa brasileira. Aliás, Lemond observou:

Atualmente a América Latina inteira esta sendo percorrida por uma onda de nacionalismos que se traduz, sobretudo, pelo desejo de se libertar do jugo econômico do colosso norte-americano e que tem por conseqüencia de chamar a atenção desses países para a Europa, onde a França recuperou seu lugar de grande nação; essa tendência esta particularmente visivel no que concerne o Brasil. (LEMOND, 1958)
Tirar proveito do não alinhamento político de países latino-americanos equivalia, na ideia do adido, a valorizar as relações com a França. Na introdução de seu relatório, Lemond denotava entusiasmo com relação a chegada do general de Gaulle ao poder, em maio de 1958, acreditando que o fortalecimento do poder executivo traria melhoras no processo de tomada de decisões. Com efeito, De Gaulle entendia dar nova orientação a política externa francesa, insistindo em sua autonomia com relação aos Estados-Unidos e à União Soviética. Muitos de seus conselheiros, como o deputado Louis Joxe, acreditavam que, somente após resolver seus problemas internos, a França poderia planejar uma política externa independente. A França se voltou para as negociações dentro da aliança Atlântica, no sentido de rever suas posições; determinou que a prioridade do governo era por fim a Guerra da Argélia; e insistiu numa cooperação com a Alemanha, a fim de favorecer a construção da Comunidade Econômica Européia. França e Brasil se distanciavam nos rumos da diplomacia.

Apesar do entusiasmo do adido militar, dois meses antes, durante o encontro que marcou o relance das relações bilaterais, o embaixador Bernard Hardion e o ministro das Relações Exteriores Negrão de Lima muito discutiram acerca das tradicionais afinidades entre o povo brasileiro e o francês, ao relembrarem laços que ligavam a história de ambos países. No entanto, muito pouco decidiram. A conversa entre os dois diplomatas gravitou em torno do impulso que o Governo brasileiro entendia dar a sua política pan-americana e a respeito da questão argelina, que afetava a imagem da França no exterior.

No entender do presidente Kubitschek como no seu, a nova orientação política que o Brasil desejava dar a ação conjunta das Nações latino-americanas não implicava numa distensão das relações com a Europa. O Brasil não desejava manter-se numa relação muito estreita com os Estado Unidos e precisa do con- 
tra-peso que representa a Europa (HARDION, 1958).

O historiador Paulo César Vizentini insiste sobre a importância de fatores econômicos, em particular o fim do "milagre", para explicar a volta de cores nacionalistas à diplomacia brasileira. A partir de 1958, fatores externos e internos levariam o governo Kubitschek a retomar uma ativa política externa de barganha face aos Estados Unidos. Nesse sentido, havia certas semelhanças com o impulso nacionalista que de Gaulle dava à política externa francesa: a aproximação com a Europa era encarada como um meio de obter capitais para investir no desenvolvimento econômico, sem perder o canal norte-americano (VIZENTINI, 2004, p. 98-100).

A América Latina e o Brasil atravessavam então período de fortes conflitos políticos e sociais. Com a vitória das tropas castristas em Cuba, o continente entrava na Guerra Fria e introduzia maior complexidade no cenário internacional. Em outubro de 1960, Jânio Quadros, então candidato à presidência da República, viajou para Cuba acompanhado do advogado das Ligas Camponesas Francisco Julião. Eleito presidente, Quadros teve dificuldades em manter uma linha de conduta clara, que permitisse o desenvolvimento do diálogo com a França.

À relativa facilidade de contato que se estabelecera durante os primeiros anos do governo Kubitschek, se sucedeu um diálogo distante e a partir de 1959 as relações com a Europa mudaram substancialmente (LESSA, 2000). A França e a Europa representavam um contrapeso à influência norte-americana, mas não se tratava de uma prioridade para o Itamaraty: desde a V reunião de consulta dos chanceleres americanos, em Santiago do Chile, em 1959, o Itamaraty chamava a atenção do Departamento de Estado acerca dos problemas latino-americanos e reiterava os principais pontos levantados na Operação Pan-americana (OPA)
(VIZENTINI, 2004, p. 113). O embaixador francês e o adido se entusiasmaram com a possibilidade de aumentar a presença da França no Brasil, no entanto, dois anos após o início da OPA, o Brasil ocupava apenas a $14^{\mathrm{a}}$ posição dentre os compradores de produtos franceses: a expansão econômica francesa não denotava nenhum progresso e o comércio de bens e materiais de equipamentos registrara um importante declínio naquele ano (HARDION, 1960). Em outras palavras, a nova orientação política do Itamaraty dava ênfase às relações interamericanas, o que distanciava a diplomacia brasileira de seus parceiros europeus. O pequeno volume do comércio franco-brasileiro não justificava tampouco maior atenção por parte das autoridades ao caso do Brasil. Fora necessário a atuação do adido, Henri Lemond, para que uma agenda militar fosse estabelecida.

No início de 1961, a questão da cooperação técnica e militar com a França entrou novamente na pauta de discussões do Estado-Maior. No entanto, depois de uma reunião entre o adido francês e o ministro da Guerra, Odílio Denis, o ministro deixou claro que cortes orçamentários inviabilizariam a cooperação militar, em particular no que dizia respeito à criação de uma missão militar francesa (BAYENS, 1961). O ministro pedia paciência, alegando que o atual governo ainda não tivera a ocasião de estabelecer um projeto de política externa. Ao acenar mudanças nos rumos de sua diplomacia, o novo governo deu razão ao adido que encarava a situação como uma oportunidade para defender os interesses franceses, em uma tentativa de suplantar a presença norte-americana. Henri Lemond era prudente quanto à concorrência com os Estados-Unidos, afinal era uma concorrência desigual, pois os meios investidos eram desproporcionais. O mais indicado era aproveitar qualquer oportunidade de defender os interesses franceses. A política externa tomaria rumos distintos do esperado pelo ministro Odílio Denis. Após a renúncia de Quadros, a chegada ao poder de João Goulart, em 1961, 
levaria a profundas mudanças nas relações francobrasileiras. Em menos de dois anos, as relações francobrasileiras chegariam a um impasse, com o episódio que se convencionou chamar de Guerra da Lagosta, confirmando a tendência ao afastamento entre os chefes de Estado.

O desentendimento se estendeu por três anos, devido à falta de tato do ministro da Marinha do Brasil, almirante Suzano, que mobilizara a frota de navios de guerra brasileira para escoltar os lagosteiros franceses, e da falta de sensibilidade do general de Gaulle, ao enviar contra-torpedeiros para proteger os mesmos navios pesqueiros. Esse episódio revelava o estado precário das relações entre o governo Goulart e o do general de Gaulle. Somente não se tornou uma tragédia graças à capacidade da diplomacia em lidar com conflitos políticos e evitar o confronto militar (LESSA, 1999). A crise serviu de argumento tanto para a oposição criticar o governo, quanto para o próprio governo se afastar de uma situação conflitante em um Nordeste agitado pela esquerda e por representantes de interesses privados estrangeiros.

Os problemas relacionados à pesca intensiva da lagosta paralisaram o diálogo oficial (ARAUJO, 2011). A crise com os lagosteiros coincidiu com a chegada à embaixada de Pierre Lallart, cujas atividades passaram a se concentrar na contrainformação e espionagem das atividades brasileiras, em particular no âmbito da marinha de guerra. A paralisia no diálogo oficial e o fato de muitos dos contatos estabelecidos por Henri Lemond terem deixado os cargos de confiança que ocupavam, levou Pierre Lallart, a estabelecer contatos com a oposição, que passaria então a constituir sua principal rede de interlocutores.

\section{A embaixada francesa e o arquipélago das conspirações}

Lallart passou a frequentar políticos e militares de direita e extrema-direita, como o general Franco Pontes, comandante da Força Pública de São Paulo, Miguel Reale, secretário de segurança de São Paulo, e empresários membros dos holdings CONCLAP (Conselho Superior das Classes Produtoras) e CONSULTEC (Companhia Sul-Americana de Administração e Estudos Técnicos) (LALLART, 1965). Ao seguirmos suas as redes de relações, encontramos membros ativos do grupo de pressão parlamentar IBAD (Instituto Brasileiro de Ação Democrática) e do think thanks IPES-São Paulo. Dentre os principais interlocutores de Lallart encontravam-se Augusto Frederico Schimdt, responsável por estudos técnicos para a cooperação Europa e Brasil e paralelamente representante no IPES-SP das companhias francesas Ciments Lafarge, Société des gérances et participations financières, Potasse et Produits chimiques, Société générale maritime, Fabrique de produits chimiques de Mulhouse, Société de produits chimiques et des terres rares. No comitê diretor do IPES-SP, Paulo Reis Magalhães representava as empresas Rhodia, Rhône Poulenc e Valisières. A análise comercial no think thank encontrava-se em mãos de João Mello Flores, representante da companhia francesa Schneider e Cia. (DREIFUSS, 1981p 87) Nesses grupos de estudos se reuniam também oficiais que haviam deixado o governo com a chegada de Goulart e com quem Lallart dialogava frequentemente: Golbery do Couto e Silva, Orlando Geisel, Ernesto Geisel, Aurélio de Lira Tavares, Jurandir de Bizarria Mamede, Heitor Herreira, Edson de Figueiredo, Geraldo de Menezes Cortes, Idálio Sardemberg, Belfort Bethlem, João Bina Machado, Ademar de Queiróz e os generais Cordeiro de Farias e Juarez Távora (LALLART, 1963). 
Por mais de três anos, coronel Lallart enviou relatórios, pareceres e notas ao chefe do serviço secreto francês - SEDECE - em que detalhava a radicalização dos militares das três forças e a posição das empresas francesas diante da situação político-militar. Ele aproveitou a oportunidade para consolidar laços institucionais, mediante acordos de cooperação entre as polícias militares de Minas Gerais, São Paulo e Rio de Janeiro, que passaram então a receber instruções específicas, voltadas para o combate contrarrevolucionário (LALLART, 1963). Outros acordos foram firmados com a própria Academia Militar das Agulhas Negras, em Resende, que também passaria a receber instrutores franceses.

Visitas protocolares aproximavam militares brasileiros e franceses, como em janeiro de 1963, quando o tenente-coronel Meira Mattos viajou para França, a fim de recolher material bibliográfico e encontrar o comandante da Escola Militar de Saint Cyr. Alguns meses mais tarde, o general Ribeiro de Carvalho, encarregado pelo Estado-Maior da Aeronáutica de estudar helicópteros de fabricação francesa, da empresa Sud Aviation, encontrou-se com o general Fay, presidente do Office Français d'Exportation d'Armement. O embaixador francês no Brasil, Jean-Paul Angles, notificou a respeito dessas duas missões que elas contribuíam para a cooperação técnica e militar, ao dar corpo e sentido ao acordo assinado anos antes, que até então havia logrado poucos resultados (ANGLES, 1963).

Políticos notoriamente conservadores, como Adhemar de Barros, governador do estado de São Paulo, Carlos Lacerda, do estado da Guanabara, e Júlio de Mesquita Filho, dono do jornal O Estado de São Paulo, mantinham relações freqüentes com o adido militar, com o cônsul francês de São de Paulo e com o embaixador no Rio de Janeiro (LALLART, 1963). Mais um indício do estreitamento de laços entre políticos conser- vadores dos dois países veio a intervir em maio de 1963, quando Magalhães Pinto, governador de Minas Gerais, recebeu o ex-ministro francês das Relações Exteriores, Georges Bidault, que pedira refugio à embaixada do Brasil em Lisboa (LIMA, 1963).

Assim escrevia o embaixador Raul Vicenzi, ao ministro das Relações Exteriores, Hermes Lima, a respeito do ex-ministro francês:

Embora não me seja possivel afirmar a autenticidade do anexo à carta do "Conseil National de la Résistance" (órgão diretor da Organização do Exército Secreto) a orientação que ela estabelece é de tal maneira coincidente com as informações obtidas pela embaixada e com o clima de frieza caracterizada ora existente nas relações entre os dois países, que julgo deva ela merecer a mais cuidadosa atenção de nossa parte (LIMA,1963).

Cabe aqui esclarecer alguns elementos, para compreender o que acontecia entre a França e o Brasil, naquele momento delicado da história dos dois países. Embora fosse notória a riqueza da experiência desses políticos e militares que buscavam refúgio em países da América do Sul, o governo brasileiro teve de abrir mão de acolher alguns deles, que acabaram por receber refúgio na zona do canal do Panamá (LYMA, 1963).

Embora o final da Guerra da Argélia tenha liberado muitos militares das missões de manutenção da ordem interna no departamento francês do norte da África, o desprendimento dessa antiga colônia causou grande ressentimento em uma determinada elite política e militar francesa. Fazia parte desse restrito grupo de pessoas, o antigo adido militar francês no Brasil, coronel Henri Lemond, alguns militares que ofereceram seus serviços como particulares à determinadas empresas de segurança, e políticos influentes como o ex primeiro ministro francês Georges Bidault. Alguns deles participaram de organizações clandestinas oriundas da Orga- 
nização do Exército Secreto (Organisation Armée Secrète - OAS), sem que oficiais membros desta organização, composta por sediciosos civis e militares, tenham participado diretamente (DAR, 2013, p. 12). O governo brasileiro, como seu vizinho argentino, acolheu alguns militares franceses sediciosos, antes e depois do putsch dos generais de Argel de 1961, mas nenhum estudo sistematizado avaliou a importância desse número e somente alguns arquivos esparsos permitem constatar a presença no Brasil de membros do Comitê Nacional de Resistência, ramificação da OAS. Após a independência, essas organizações se dedicariam a preparar atentados contra Charles de Gaulle, encarado como responsável pelo fiasco na Argélia.

Era difícil controlar a atividade dessas pessoas, cuja grande maioria vivia na clandestinidade ${ }^{1}$. Somente os mais notórios eram objeto de artigos de imprensa ou de notas do Itamaraty. Em 1963, o governador de Minas Gerais Magalhães Pinto e a colônia francesa de Belo Horizonte deram uma grande recepção a um dos principais líderes do Comitê Nacional de Resistência, organização terrorista de extrema-direita, Georges Bidault (JORGE, 1964). O ministro francês já havia passado pela Suíça e por Portugal, onde encontrou o embaixador do Brasil em Lisboa, Negrão de Lima, a quem solicitou visto (ALVES, 1963). Após alguns meses em uma fazenda em Diamantina, seguiu, no início de 1964, para Campinas. Seriam necessárias pesquisas mais profundas, em arquivos do governo de Minas Gerais e do próprio Itamaraty, para elucidar a atividade de Georges Bidault no Brasil. O ex-ministro exilou-se no país até 1967, quando pediu asilo ao governo da Bélgica.

Em outras palavras, a crise entre o governo francês e o brasileiro se deu em torno dos chefes de Estado, que se consideravam ofendidos com os ataques da imprensa. Embora houvesse o General reclamado o congelamento das relações franco-brasileiras, ele não podia controlar todos os aspectos destas, pois sempre haveria alguém para burlar a eficiência de seu serviço de inteligência. Aliás, desde março de 1964, tanto os serviços consulares quanto o adido militar francês avisaram o Primeiro ministro, Georges Pompidou, da forte oposição ao governo Goulart.

Enquanto Lallart esteve à frente da pasta de assuntos militares na embaixada francesa, a pauta de discussão dos assuntos militares adquiriu certa autonomia com relação às questões diplomáticas. $\mathrm{O}$ adido assumiu posições cruciais que se revelariam decisivas para os rumos da diplomacia francesa no Brasil. Ele aconselhou diretamente o presidente Charles de Gaulle a reconhecer rapidamente o governo provisório de Ranieri Mazzini ou pelo menos a anunciar sua simpatia para com os novos donos do poder.

\section{Visões do golpe}

Os dias que se seguiram a queda de Goulart foram marcados pela intensa correspondência entre o adido militar e os responsáveis políticos no Rio e em Paris. Entre 31 de março e $1^{\circ}$ de abril de 1964, a embaixada francesa e a britânica estavam em estado de alerta acerca da grande mobilização militar, advertidas por Vernon Waters, chefe da missão militar dos Estados Unidos no Brasil. Também o adido militar francês fora informado por seus colaboradores sobre as intensas atividades políticas nos estados de Minas Gerais, São Paulo e Guanabara, e sobre os complôs que se formavam contra o chefe de Estado. A intensa troca de telegramas entre a embaixada e a Secretaria de Estado para a América atestava da gravidade da situação. Em menos de

\footnotetext{
${ }^{1}$ Segundo Marie-Monique Robin, alguns membros da organização cederam seus serviços como mercenários a governos da América Central, outros como instrutores em escolas militares norte-americanas e poucos como auxiliares técnicos para o Exército argentino. No entanto, essas informações são embasadas unicamente nas declarações de oficiais do Exército francês.
} 
dois dias caía o presidente João Goulart, deposto por um golpe de Estado que resultou da aliança entre elites civis e militares.

A rapidez com que o Departamento de Estado de Washington reagiu à crise foi proporcional aos interesses envolvidos no golpe. A reação do presidente Jonhson legitimava o golpe (FICO, 2009, p. 89). Hervé Alphand, embaixador francês em Washington informava a Secretaria de Estado para a América, em Paris:

O Departamento de Estado, o que acompanhou com muita atenção e preocupação os desdobramentos da crise brasileira desencadeada pela revolta dos suboficiais da Marinha, se mostrou satisfeito e surpresa pelo desfecho atual dos acontecimentos. Nossos interlocutores negamse a expressar qualquer simpatia por um ou outro dos muitos protagonistas, no entanto, ninguém pode negar que a saída de Goulart vai melhorar profundamente as relações entre os Estados Unidos e o Brasil (ALPHAND, 1964).

O diplomata francês parecia contentar-se das explicações de Dean Rusk, Secretário de Estado dos Estados Unidos: Mazzili chegou ao poder por vias constitucionais, o que segundo Hervé Alphand não podia ser comparado aos golpes militares que ocorreram em outras repúblicas do hemisfério (ALPHAND, 1964b).

No entanto, desde o Rio de Janeiro, Jean-Paul Angles, responsável de negócios da França no Brasil, evocava uma situação extremamente grave, apesar de sublinhar que "não houve combates, nem no Rio nem nos estados onde se manifestou a rebelião". Ele completa: "É uma tradição revolucionária brasileira [...] cada chefe avalia suas forças e comparando-as com as de do campo oposto determina o vencedor" (ANGLES, 1964). Pierre Lallart continua a mesma analogia em seu relatório: "a Revolução já foi jogada e terminou como uma partida de xadrez. Não se toma o rei. Basta deslocar as peças e colocá-lo em xeque e mate" (LALLART, 1964). Enquanto Lallart preocupava-se em analisar as redes envolvidas na organização do golpe, Angles, apesar de satisfeito com desfecho da crise, atentava à fraca base constitucional do novo regime (ANGLES, 1964b). Além da analogia ao jogo de xadrez, representativo da cultura política dos dois homens, observa-se que ambos insistiam sobre a natureza pacífica e cordial do povo brasileiro, mais predisposto a preservar a vida de seus compatriotas do que a derramar sangue por razões políticas. Ainda segundo Angles, o país estava por fim aliviado ao saber que escapou da guerra civil.

Enquanto a presidência da república ficou em mãos do presidente da Câmara, Ranieri Mazzili, a França não se posicionou nem a favor nem contra, deixando pairar a incerteza quanto o reconhecimento do governo interino. A intensa troca de correspondência entre a embaixada no Rio e o Departamento de Estado em Paris denotava atenção especial dos representantes diplomáticos acerca do respeito à legalidade. Uma das principais exigências das autoridades diplomáticas era a manutenção de ao menos uma aparência de legalidade, para evitar qualquer possível analogia com outras ditaduras militares que abalavam as democracias latino-americanas (ANGLES, 1964b).

A imprensa francesa recebeu com pouco entusiasmo o golpe. Segundo Raul de Vicenzi, embaixador do Brasil, a grande imprensa parisiense foi quase unânime a denunciar o golpe de Estado, visto como uma degradação da crise e não sua conclusão. Os jornais afirmavam que se tratava de uma regressão sem precedentes no âmbito dos direitos sociais e anteviam a possibilidade de instauração de um regime de extrema-direita. Vicenzi chegou a pedir entrevista com Couve de Murville, ministro das relações exteriores, mas encontrou unicamente o encarregado de negócios, Louis Joxe. Joxe garantiu a Vicenzi que a opinião do governo era diferente da que era expressada nos jornais (VICENZI, 1964). 
Os novos donos do poder se apressaram em reorganizar o governo, excluindo todos aqueles que tinham participado da gestão anterior. As mudanças ministeriais, como todas aquelas nas secretarias de Estado, provocaram grande apreensão nos diplomatas e investidores franceses, que temiam rupturas nos contratos. A atitude francesa era de reserva, devido à incerteza acerca da continuidade da agenda bilateral. Durante esse curto ínterim, a direção nacional da Agência Francesa de Imprensa (AFP) enviou a seu represente no Rio de Janeiro telegrama recomendando que se mantivessem os correspondentes de imprensa no Brasil; pedia também que se esforçassem para garantir informações objetivas, completas, buscando manter, por seus próprios meios, a segurança de seus agentes. Aliás, a AFP indagava-se sobre a possibilidade de a censura ser bilateral, oficializada pelos dois governos (AFP, 1964).

À divulgação da composição do novo Governo, seguiu-se uma atitude pragmática de reconhecimento, sem a tradicional troca de telegramas entre chefes de Estado. Para compensar a posição negativa e defender um rápido reconhecimento do governo golpista, o coronel Pierre Lallart, adido militar francês no Brasil, escreveu ao ministro das Forças Armadas, Pierre Messmer, exigindo atitude mais enérgica do Governo francês:

Declaro ao Ministério das Forças Armadas que estou pessoalmente muito menos pessimista que correspondente imprensa francesa sobre situação atual e futura. Tendo superestimado organizações de esquerda, conhecem pouco importância e "espirito" das Forças Armadas, e encontram hoje dificuldades para recriar clima. [...] Fato de oficiais circularem em uniforme e armados é somente símbolo. Castelo Branco que conheço bem é elemento confiável. Devido à personalidade do General Castelo Branco, suas afinidades com a França e suas responsabilidades sua nominação poderia abrir-nos ambitos político e militar, penso a título estritamente pessoal que seria aconselhável França não demorasse muito tempo para manifestar sua simpatia se estiver realmente decidida. Simples mensa- gem do chefe de Estado seria evidentemente de natureza a facilitar nosso restabelecimento aqui (LALLART, 1964).

Para o adido, chegara o momento da França assumir posição de liderança na América Latina, se posicionando a favor do novo governo. O militar e o diplomata se contradiziam. Pierre Lallart pretendia levar de Gaulle a apoiar rapidamente os novos donos do poder, tornando a França um aliado incondicional do novo regime. $\mathrm{O}$ governo francês só reconheceu o novo regime após a eleição de Castello Branco, no momento da cerimônia de posse.

Entre 1963 e 1965, o adido militar representa a continuidade das questões políticas na embaixada da França no Brasil. Enquanto um só adido coordenou as atividades de informação no Brasil, dois embaixadores e três responsáveis de negócios tentaram sem sucesso dirigir as relações políticas. A atuação de Pierre Lallart foi nesse sentido essencial para a normalização das relações bilaterais. A expressão diplomata de farda não era, portanto, somente uma figura de linguagem (LALLART, 1966).

Os relatórios de Lallart insistiam aliás sobre o anticomunismo ou a guerra revolucionária para defender diante de seus interlocutores em Paris sua visão do golpe como um movimento natural, próprio a favorecer a normalização das relações bilaterais, tão limitadas desde a chegada de Goulart.

Lallart foi testemunha ocular do golpe. Segundo ele, o trabalho de propaganda e organização política conduzido pelos distintos grupos conspiradores neutralizou o governo Goulart:

Muito bem elaborado, executado em dois dias e através de um país 17 vezes maior que a França, quase sem confrontações nem derramamento de sangue, esta operação foi técnicamante exemplar. Se a ação dos grupos de choque parece ter sido reduzida durante os acontecimentos, 
no entanto as redes têm desempenhado um papel bastante importante de infiltração, propaganda, inteligência e infraestrutura. [...] Depois da Revolução, esses grupos clandestinos autônomos podem representar um problema para o exército, sem dúvida, preocupado com a multiplicidade de organizações cuja ajuda foi inestimável, mas que escapam de seu controle (LALLART, 1964c).

Primeiro de uma série que marcou a Guerra Fria na América Latina, o golpe civil e militar de 1964 aparecia como um novo modelo, inspirado de alguma forma no movimento militar que derrubara a $4^{\mathrm{a}}$ República francesa, empossando o general de Gaulle, em 13 de maio de 1958. Realizado em menos de três dias, com telefonemas, movimento de tropas e cálculos de poder, o golpe confirma a importância desempenhada pelas forças militares e policiais estaduais e nacionais na política nacional.

Durante os anos 1964 e 1967, Pierre Lallart esteve à frente dos assuntos militares e legou uma densa rede de oficiais e políticos castelistas a Jean Wartel, oficial que como seus predecessores tinha experiência nas guerras coloniais. Ao passar seu cargo à Wartel, Lallart compôs um vasto relatório sobre a "revolução brasileira" e usou a expressão gatilhos para definir o comportamento dos militares no poder. A palavra servia para representar dois tempos da organização do poder e logo seria retomada para definir o impacto da repressão. Muitos documentos da época mostram a preocupação dos diplomatas com a imagem do regime no exterior e buscam saber qual seria o possível impacto na economia.

Segundo Pierre Lallart, o primeiro "disparo revolucionário" ocorreu já em 1964 com o primeiro Ato Institucional e, em 1965, o AI-2 marcou o segundo disparo. Ocorreriam muitos outros disparos contra a democracia, mas já naquele momento, Lallart reconhecia: “o Exército acaba de mostrar que além de seu papel de
Poder Moderador, ele se ergueu ao nível de verdadeiro Poder Miliar, praticamente como um dos três poderes" (LALLART, 1965). Após o primeiro ímpeto repressor, o regime tendeu a se institucionalizar, com a progressiva militarização das forças policiais e a reforma do Conselho de Segurança Nacional que aumentou a participação de militares nesses órgãos. Desde maio de 1965, o embaixador francês no Brasil, Pierre Sébillau, insistia: "o governo dos estados e os militares alimentam um ambiente de insegurança com o intuito de intervir em qualquer momento e desse modo aumentar o papel de gloriosos salvadores do novo regime" (SEBILLAU, 1965).

Insurreições fracassadas ou levantes militares precipitados são oportunidades para a cristalização de correntes radicais nas Forças Armadas. Segundo os serviços franceses era difícil determinar se a ação do governo respondia às atividades da extrema esquerda ou se precedia os atentados cometidos que tinham por alvo o chefe de Estado e seus ministros.

\section{O estreitamento das relações}

Os serviços de informação da embaixada estavam muito bem informados sobre a movimentação militar que ocorria, sobretudo acerca dos oficiais diplomados da Escola Superior de Guerra francesa. A grande quantidade de documentos conservados nos acervos do Serviço de Documentação Exterior e de Contraespionagem indica forte cooperação entre militares brasileiros e francesas, em particular depois do golpe.

Desde abril de 1964, Lallart chamava a atenção para o grupo da Sorbonne, que, segundo ele, eram oficiais intelectuais e ativos, célula mãe da conspiração, coordenadores da maioria de redes militares e organizações civis (LALLART, 1964c). O nome lembrava tanto o caráter intelectual dos oficiais que haviam cursado parte de sua formação no exterior como a inspiração 
francesa do grupo que estudava o marxismo e a guerra revolucionária. Além dos generais Castello Branco, Penna Brasil, Aurélio de Lira Tavares, formavam parte do grupo Alfredo Souto Malan, Jurandir de Bizarria Mamede, Walter de Menezes Paes e Moacir Barcellos Potiguara. Todos mantinham laços pessoais ou profissionais com a França e liam textos franceses de oficias que haviam combatido nas guerras coloniais (ARAUJO, 2012). A presença desses oficiais nos escalões da burocracia do Estado criava um espaço de diálogo até então inédito entre a França e o Brasil.

Pierre Lallart matinha relações pessoais e cordiais com oficiais castelistas que ocupavam então cargos de confiança no governo, como Ernesto Geisel, chefe do gabinete do presidente da República, e Golbery do Couto e Silva, chefe do Serviço Nacional de Informações (LALLART, 1965). Segundo Lallart, Golberi seria o verdadeiro arquiteto do regime, "ao mesmo tempo Fouché e Talleyrand" (LALLART, 1966). A comparação com o período revolucionário francês, sobretudo com dois personagens ambíguos que souberam sobreviver à revolução, participando em todas decisões, seja durante o terror seja durante a restauração. Joseph Fouché incarna a sombra da revolução, responsável por grande número de execuções durante o Terror, chefe da policial imperial de Bonaparte e disposto a alianças contranatura com políticos conservadores e contrarrevolucionários. Enquanto Charles de Talleyrand, bispo envolvido com a abolição dos privilégios do clero se distinguiu por suas fidelidades sucessivas, sempre ao lado do poder, sempre disposto a servir a França. Segundo Lallart, Golbery seria um homem de muitas faces.

As relações entre serviços de informação de ambos países se reforçaram durante todo o período ditatorial, em particular durante os preparativos para a visita do presidente francês. Em outubro de 1964, a visita de Charles de Gaulle criou um espaço de diálogo entre serviços de informação. Segundo a visão do general de Gaulle, os serviços de informação estão ao serviço do governo e nesse sentido não podem ser considerados seus parceiros. A subordinação da comunidade de segurança e informação à política está diretamente ligado ao projeto de poder desenvolvido durante os anos pelo governo francês. Desde junho de 1964, Maurice Grimaud, diretor geral da Segurança nacional, no ministério francês do Interior, entrou em contato com seus equivalentes brasileiros, no intuito de preparar os serviços de segurança da embaixada a garantir a defesa e a proteção da comitiva francesa. A lembrança do assassinato de John Kennedy em Dallas, um ano antes, os nove atentados cometidos contra de Gaulle e a presença de vários membros da OAS no Brasil e na América Latina reforçavam a ideia de uma ameaça permanente (ARAUJO, 2016). Nesse sentido, três oficiais com experiência na proteção de pessoas foram enviados à embaixada da França no Rio de Janeiro (SEBILLAU, 1964). Do lado brasileiro, Alfredo Souto Malam fora designado pelo ministro da Guerra, Costa e Silva, para acompanhar Charles de Gaulle em sua visita ao Brasil, mantendo nesse sentido estreitas relações com Piette Lallart (LALLART, 1964d).

As relações bilaterais se militarizavam de ambos os lados. Entre 1964 e 1969, as relações entre os dois países seriam marcadas pela presença de militares em muitos fóruns de discussões e contribuiriam a restabelecer as relações bilaterais.

Outro fator de aproximação entre serviços de informação foi criado pela onda de exilados políticos que deixava o Brasil com destino à França. Logo após o golpe, a primeira onda de políticos envolvidos com o governo Goulart deixou o Brasil em direção aos países latino-americanos. Diplomatas e adidos militares manifestaram o interesse em observar e acompanhar esses 
viajantes políticos em suas distintas trajetórias. No entanto, os informes mais alarmantes seriam produzidos no início dos anos 1970, na embaixada do Brasil em Paris e no próprio ministério das Relações Exteriores, em Brasília. De certa forma, o interesse por militantes que cruzavam o Atlântico estimulou a implantação de observadores políticos nas missões diplomáticas de distintos países europeus, cuja missão era fornecer dados sobre essas pessoas. Desde então se criou um precário núcleo de coleta, análise e produção de informações que logo orientou as atividades desse seleto núcleo de civis e militares para a observação da atividade política de um grupo peculiar de "banidos": os militantes da esquerda armada refugiados na Argélia.

Em 24 de maio de 1965, Miguel Arraes, exgovernador de Pernambuco, asilou-se na embaixada da Argélia, seguindo no dia 16 de junho para Argel. Contrariamente a outros exílios, esse não passou desapercebido. O diretor da Secretaria de Estado das Relações Exteriores, Azeredo da Silveira, pedia cautela e muita atenção quanto ao exílio de Arraes, que dispunha então de salvo-conduto (AZEREDO, 1965). Durante o exílio, o ex-governador de Pernambuco escreveu textos e travou contatos com movimentos de libertação nacional africanos. Em 1969, ele criou em Argel, junto com Márcio Moreira Alves, Almery Bezerra e Everaldo Norões, a Frente Brasileira de Informações (FBI), ligada a organizações de esquerda e de oposição ao governo militar do Brasil. A denúncia da violência política, em nome da democracia e dos direitos humanos, vinha do exterior, divulgada por grupos de políticos influentes.

Era de se esperar uma reação do governo brasileiro, da mesma maneira como havia reagido anteriormente acerca da imprensa francesa. A imagem do Brasil no exterior constituía um fator central na lógica de legitimação dos governos militares, que buscavam manter assim ao menos uma fachada de legalidade. Pode-se supor que tal atitude estivesse relacionada aos interesses econômicos e ao fato de algumas empresas estrangeiras recusarem negócios com ditaduras escancaradas.

A intensificação tanto da repressão como da luta armada no Brasil levou ao banimento de número cada vez maior de cidadãos. Em junho de 1970, a Ação Libertadora Nacional e a Vanguarda Popular Revolucionária sequestraram no Rio de Janeiro o embaixador alemão Enfried Von Hollenben, solto em troca da libertação de 44 presos políticos (CHIRIO, 2005). Solicitado por esses dois grupos armados, o governo argelino concordou em receber os 40 prisioneiros políticos, que da embaixada da Argélia seguiram pouco tempo depois para aquele país. A chegada desse grupo de jovens revolucionários brasileiros preocupou o Quai d'Orsay, que recebeu incessantes pedidos para que fossem recusados os vistos de entrada na França aos 40 prisioneiros políticos, evitando a livre circulação no espaço mediterrâneo. A Direção Geral da Polícia Nacional francesa solicitava então ao ministro das Relações Exteriores informações e cooperação (ROLLAND, 2008).

O medo de ver o banidos exilados em Argel chegar na França levou à mobilização dos serviços secretos franceses, tanto para a Divisão de Segurança e Informações do ministério das Relações Exteriores quanto o Centro de Informação do Exterior acreditavam que esse grupo de exilados se organizariam em uma organização internacional com o objetivo de difamar a imagem do Brasil no exterior e pôr um fim ao regime militar. A paranoia coletiva mostrava-se eficiente. Com a mudança de regime na Argélia, o aumento do controle exercido pela polícia levou alguns líderes a se mudar para Paris, o que agravou a situação, pois a polícia francesa conhecia muito pouco as atividades passadas dos exilados. Foi então decidido que o Diretório Central do Serviço de Informações e a Direção do Serviço de Informações da Polícia Nacional, assistidos pela Divisão de 
Segurança do Território colheriam informações sobre as atividades "subversivas", a hospedagem e a situação administrativa dos principais integrantes da rede brasileira. Aliás, o Serviço de Documentação Exterior e de Contraespionagem procedeu à busca de informações sobre os refugiados brasileiros (ROLLAND, 2008b).

Por outro lado, as embaixadas francesas e brasileiras contribuíam para enriquecer a base de dados sobre os exilados: buscavam controlar seus deslocamentos e conhecer o cunho de suas atividades no exterior, divulgando as informações a distintos órgãos de policiamento.

\section{Conclusões}

Durante o período abarcado por esse estudo, os militares foram tomados como instrumentos da política externa. Apesar de denotarem grande independência de ação no campo operacional, os adidos militares eram cientes de suas missões junto à embaixada e refletiam em conjunto sobre a projeção internacional da França. Além disso, a função de oficial de inteligência nunca era negligenciada: o adido militar produzia informes e estudos sobre o Exército, que remetia ao embaixador, ou seja, ele era o conselheiro militar da embaixada e uma fonte de informações imprescindível. Devido aos estudos sistemáticos do adido militar, a embaixada adaptou-se às configurações políticas internas que surgiam e que, em muitos casos, foram causadas pela ação de militares.

No entanto, distintas situações levaram o adido a se destacar das relações políticas, seguindo um caminho próprio, de afirmação da presença militar francesa no Brasil. O episódio da Guerra da Lagosta (1961-1963), por exemplo, teve poucas repercussões nas relações militares, que pareciam menos submetidas a variações ideológicas. Aos poucos ficou claro que os interesses dos novos responsáveis do Itamaraty conflitavam com aqueles dos chefes do Exército. Diante da dificuldade de articular um equilíbrio entre interesses diplomáticos e militares, tornava-se difícil orientar a política do Exército no sentido de prover as Forças Armadas de indústrias bélicas locais.

As relações franco-brasileiras se normalizariam com a visita do chefe de Estado francês, em outubro de 1964, que definiria a agenda bilateral e resolveria grande parte dos problemas bilaterais. A visita do chefe de Estado francês, bem como a chegada em Paris de numerosos exilados brasileiros levou ao estreitamento das relações entre serviços de inteligência. Apesar da conjuntura ter tido papel central nesse estreitamento, franceses e brasileiros compartilhavam determinados valores contrarrevolucionários.

Livros, artigos, cursos e conferências valorizavam os aspectos ideológicos da Guerra Fria e construíam representações do comunismo que legitimavam a importação de armas, doutrinas e ideias, em particular no âmbito dos serviços de informação. Os oficiais franceses eram então considerados especialistas incontornáveis da contrarrevolução e Paris não deixava de enviar adidos oficiais com reconhecida experiência nesse campo. 


\section{Referências bibliográficas}

Agence France Presse. Télégramme à l'adresse du correspondant de l'AFP au Brésil. 6 de abril de 1964. AMAE. Seção Amérique. Série Brésil. Pasta 127.

ALPHAND Hervé. Télégramme de l'ambassade à Washington à la Direction d'Amérique. $1^{\circ}$ de abril de 1964. AMAE. Seção Amérique. Série Brésil. Pasta 127.

127.

. Communiqué via le département à Rio. 3 de abril de 1964. AMAE. Seção Amérique. Série Brésil. Pasta

ANGLES Jean-Paul. Télégramme très urgent. 2 de abril de 1964. AMAE. Seção Amérique. Série Brésil. Pasta 127. $\overline{\text { Pasta }} 127$.

La Révolution du $1^{e r}$ avril à Rio de Janeiro. 3 de abril de 1964. AMAE. Seção Amérique. Série Brésil.

La répression révolutionnaire au Brésil $-1^{\text {er }}$ au 10 avril 1964. 10 de abril de 1964. AMAE. Seção Amérique. Série Brésil. Pasta 127.

Anônimo. Le Brésil et la politique de coopération franco-brésilienne. 15 de abril de 1960. AMAE. Seção Amérique. Série Brésil. Pasta 43.

Anônimo. Télégramme. Voyage en Europe du général Ribeiro de Carvalho. Setembro de 1963. AMAE. Seção Amérique. Série Brésil. Pasta 45.

BAYENS Jacques. Entretien du maréchal Denys avec le colonel Lemond. Março de 1961. AMAE. Seção Amérique. Série Brésil. Pasta 54.

CHIRIO Maud. "Formes et dynamiques des mibilisations politiques des exiles brésiliens en France (1968-1979)". In Cahiers des Amériques Latines, IHEAL edições, n. 48/49, 2005.

DOISE Jean, VAÏSSE Maurice. Politique étrangère de la France. Diplomatie et outil militaire (1871 - 1991$).$ Paris: Seuil, 1992 (1987).

DREIFUSS René Armand. 1964 : A Conquista do Estado. Ação política, poder e golpe de classe. Petrópolis: Vozes, 1981.

DUROSELLE Jean-Baptiste. Tout empire périra. Théorie des relations internationales. Paris: Publications de la Sorbonne, 1981.

DUROSELLE Jean-Baptiste, KASPI André. Histoire des relations internationales de 1945 à nos jours. Paris: Armand Colin, 2002 (13 ${ }^{\mathrm{e}}$ edição), t. 2.

FICO Carlos. O Grande irmão. Da operação Brother Sam aos anos de chumbo : o governo dos Estados Unidos e a ditadura militar brasileira. Rio de Janeiro: Civilização Brasileira, 2009.

cord, 2001.

Como eles agiam. Os subterrâneos da ditadura militar: espionagem e polícia política. Rio de Janeiro: Re-

HARDION Bernard. Conversations avec M. Negrão de Lima. 24 de julho de 1958. AMAE. Seção Amérique. Série Brésil. Pasta 43.

KATZ Paul. Nouveau Complot dans le Rio Grande do Sul. 7 de maio de 1965. AMAE. Seção Amérique. Série Brésil. Pasta 130.

LALLART Pierre. Demande d'assistance militaire pour la Force Publique de l'état de São Paulo. 20 de maio de 1963. SHD. Série $2^{\mathrm{e}}$ Bureau. Pasta 10T1108.

. Compte rendu mensuel. Agosto de 1963. SHD. Série $2^{\mathrm{e}}$ Bureau. Pasta 14S534.

. Telegrama. 6 de abril de 1964. AMAE. Seção Amérique. Série Brésil. Pasta 127.

. La Révolution brésilienne de 1964. Maio-julho de 1964. SHD. Série $2^{\mathrm{e}}$ Bureau. Pasta 14S537. 
. La Révolution brésilienne. Janeiro de 1965. Service Historique de la Défense (SHD). Série $2^{\mathrm{e}}$ Bureau. Pasta 10T1109.

. Rapport annuel de l'attaché militaire pour l'année 1964. 22 de janeiro de 1965. SHD. Série $2^{\mathrm{e}}$ Bureau. Pasta 10T1108.

. Rapport de fin de mission au Brésil. 11 de agosto de 1966. SHD. Série $2^{\mathrm{e}}$ Bureau. Pasta 10T1108.

LEMOND Henri. Le Brésil et la défense de l'Atlantique Sud. 1958. Archives du ministère des Affaires étrangères (AMAE). Seção Amérique. Série Brésil. Pasta 42.

LESSA Antonio Carlos. "A Guerra da Lagosta e outras guerras: conflito e cooperação nas relações França-Brasil (1960-1964)”. In Cena Internacional, ano 1, n. 1, 1999, p. 109-121.

. "Os vértices marginais das vocações universais: as relações entre a França e o Brasil de 1945 a nossos dias”. In Revista brasileira de política internacional, n. 43, 2000, p. 28-58.

LIMA Hermes. Relações franco-brasileiras. 7 de maio d 1963. Arquivo do Ministério das Relações Exteriores (AMRE). Seção de Correspondência Especial.

LYMA Everaldo Dayrell de. Imigração argelina. Gestões do emissário brasileiro. 11 de setembro de 1961. AMRE. Documentão ostensiva. Telegramas da embaixada à secretaria de Estado.

MOTTA Rodrigo Patto Sá. Em guarda contra o perido vermelho: o anticomunismo no Brasil (1917-1964). São Paulo": Perspectiva, FAPESP, 2002.

NABUCO DE ARAUJO Rodrigo. Conquête des esprits et commerce des armes. La diplomatie militaire française au Brésil (1947-1974). Tese de doutorado de história. Toulouse: Universidade de Toulouse 2 Le Mirail, 2011.

. "L'art français de la guerre : transferts de la doctrine de la guerre révolutionnaire au Brésil (1958-1974)". In Cahier des Amériques latines, IHEAL edições, n. 70, 2012/2, p. 39-58.

ROBIN Marie Monique. Les escadrons de la mort. L'école française. Paris : La Découverte, 2004.

ROLLAND Denis. Le Brésil des gouvernements militaires et l'exil 1964-1985. Violence politique, exile t accueil des Brésiliens en France témoignages et documents.

SEBILLAU Pierre. Note de l'ambassade de France à l'Itamaraty. 10 de setembro de 1964. AMRE. Documentão ostensiva. Notas.

SILVEIRA Azeredo da. Telegrama confidencial. Junho de 1965. AMRE. Seção de Correspondência especial.

VAÏSSE Maurice. La Puissance ou l'influence? La France dans le mode depuis 1958. Paris : Arthème Fayard, 2009.

VINCENZI Raul de. Situação política no Brasil. Comentários da imprensa francesa. 5 de abril de 1964. AMRE. Arquivo histórico. Telegramas da embaixada de Paris.

VIZENTINI Paulo Fagundes. Relações Exteriores do Brésil (1945 - 1964). O nacionalismo e a política externa independente. Petrópolis: Editora Vozes, 2004. 